\section{ONOMÁVEIN}

Revista semestral de lingüística, filología y traducción

\title{
Amplificar y contradecir con lo indecible. Un estudio de caso en el conflicto armado colombiano ${ }^{1}$
}

Amplifying and contradict with the unspeakable. A case study in the Colombian armed conflict

\section{Giohanny Olave}

Conicet

Universidad de Buenos Aires

Argentina

\section{(c) $\odot$}

Giohanny Olave: Instituto de Lingüística, Universidad de Buenos Aires, Argentina / Conicet, Argentina. | Correo electrónico: olavearias@gmail.com 


\section{Resumen}

Durante el primer año de la presidencia de Juan Manuel Santos, en Colombia, fue asesinado Víctor Julio Suárez Rojas, alias Rodrigo Briceño o 'Mono Jojoy', quien fuera el jefe militar de la guerrilla colombiana de las Fuerzas Armadas Revolucionarias de Colombia, FARC. En este texto examino el caso a partir de dos fuentes principales: la alocución presidencial donde se anunció la muerte de 'Jojoy' y el comunicado guerrillero que respondió expresamente a ese anuncio. El objetivo del análisis es reconstruir los recursos y los modos a través de los cuales los discursos construyen relaciones de oposición política. El caso es estudiado sobre la base teórica de la retórica contemporánea y el discurso polémico. En los resultados, presento y describo la amplificación retórica como el principial procedimiento de estructuración del discurso político en ambos textos analizados. Luego, describo el funcionamiento de la estrategia retórica de la "indecibilidad dicha”, esto es, la enunciación explícita de lo que el adversario supuestamente no puede ni debe decir en el espacio público (Olave, 2015). En las conclusiones, sostengo que los procedimientos de la amplificación y la indecibilidad son funcionales a la construcción de la oposición política en el discurso. Este tipo de recursos muestra la importancia del papel de lo silenciado en las interacciones polémicas entre el discurso insurgente y el gubernamental.

Palabras clave: violencia armada; retórica; discurso guerrillero; discurso gubernamental.

\section{Abstract}

During the first year of the presidency of Juan Manuel Santos in Colombia, Víctor Julio Suárez Rojas, alias Rodrigo Briceño or 'Mono Jojoy', commander of the guerrilla FARC, was killed. In this paper I examine that case from the spechees of president and the insurgent group. The aim is to reconstruct the resources and ways through which the speeches build relationships of political opposition. The case is studied on the theoretical basis of contemporary rhetoric and polemical discourse. The paper represents and describes the rhetorical amplification as the main method of structuring of political discourse in both texts analyzed. Then I describe the operation of the rhetorical strategy of "said unsaid", this is the explicit enunciation of what the adversary can not and should presumably say in public space (Olave, 2015). I argue that the amplification and unsayability are functional to the construction of the political opposition in the discourse. This type of resources shows the important role of the muted in the polemics interactions between FARC and government.

Keywords: armed violence; rhetoric; guerrilla discourse; government discourse

1 Este trabajo se inscribe en el marco de una tesis en curso sobre las construcciones retóricas en el conflicto armado coIombiano, dirigida por la Dra. Elvira Narvaja de Arnoux y codirigida por la Dra. Mireya Cisneros Estupiñán, en el Doctorado en Letras de la Universidad de Buenos Aires, con financiamiento del Consejo Nacional de Investigaciones Científicas y Técnicas, CONICET, 2012-2017. 


\section{Introducción}

Un mes antes de su muerte fue grabado en un documental² el guerrillero Víctor Julio Suárez, alias el 'Mono Jojoy', arengando clandestinamente a una numerosa tropa de jóvenes reclutas, en medio de la espesa selva colombiana. En el mismo campamento donde sería abatido, el inverosímil guerrillero sentenció, con estas palabras, aquello que hasta el último momento le resultó inaceptable: "no vamos a gastarnos 50 años para decir: no tiene vigencia la lucha armada".

En efecto, en 2015 se cumplieron 51 años de conflicto armado interno, entre la guerrilla de las Fuerzas Armadas Revolucionarias de Colombia (FARC) y el gobierno colombiano. El asesinato del 'Mono Jojoy', el 22 de septiembre de 2010, en una operación ${ }^{3}$ de las fuerzas armadas estatales, representa un punto de quiebre en el desarrollo de ese largo conflicto. Las razones de la importancia de ese hecho tienen que ver con la relevancia militar y simbólica de la figura de 'Jojoy' en la estructura guerrillera, debilitada al término del año 2010 (Ávila, 2011). Pero también tiene que ver con el momento político en el que aconteció: recién posesionado, el presidente Juan Manuel Santos con esta muerte demostraba la continuidad de la estrategia contrainsurgente antiterrorista, capital político más importante del presidente antecesor, Álvaro Uribe Vélez (2002-2010), de quien Santos fuera su ministro de Defensa.

Desde 1993, ‘Jojoy’ dirigía las operaciones militares de la guerrilla. Era el jefe del Bloque más grande de las FARC, que cubría siete departamentos al oriente del país, con 3400 hombres armados, aproximadamente. Entre los delitos de los que se le acusa, sobresalen los primeros secuestros de políticos y militares, desde la década del 90, y la planeación y comandancia de tomas guerrilleras a cabeceras municipales, batallones y puestos de policía: considerables derrotas militares para las fuerzas armadas del Estado. A nivel simbólico, su cercanía con el alias "Tirofijo"4 y con el campesinado colombiano, lo mismo que su carácter recio y pragmático, y su temprana vinculación con la vida guerrillera, lo hicieron una figura emblemática de la insurgencia (Bedoya, 2010; Botero, 2010; Molano, 1994).

En este texto, examino la alocución presidencial donde se anunció la muerte de ‘jojoy' y el comunicado guerrillero que respondió expresamente a ese anuncio. El objetivo del análisis es reconstruir los recursos y los modos a través de los cuales los discursos construyeron relaciones de oposición entre el gobierno y la guerrilla. La perspectiva teórica general es la retórica argumentativa francesa y el método es inductivo y relacional, basado en los postulados de la teoría fundamentada y del análisis del discurso en perspectiva interdisciplinar. El análisis de los textos elegidos sobre el asesinato de 'Jojoy' permite ver representativamente la construcción de relaciones de oposición en el discurso.

\section{Marco teórico}

En los comunicados elegidos, la disputa por el sentido de la muerte de 'Jojoy' manifiesta la oposición entre los actores. La distancia queda inscrita en los recursos y modos movilizados para presentar a 'Jojoy' como el "símbolo del terror en Colombia” (Presidencia, septiembre 23 de 2010: párr. 4), según la alocución presidencial, o como un "símbolo revolucionario de resistencia" (FARC, septiembre 24 de 2010: párr. 9), según el comuni-

2 Titulado "Antes de la tormenta" y realizado por el periodista Jorge Enrique Botero (2010).

3 La llamada "Operación Sodoma" se llevó a cabo en conjunto por la policía, la fuerza aérea y el ejército colombianos. El campamento del "Mono Jojoy" fue bombardeado luego de localizarlo a través de infiltración en el anillo de seguridad del guerrillero, de acuerdo con planes de inteligencia militar (revista Semana, septiembre 23 de 2010; periódico Eltiempo.com, diciembre 20 de 2010).

4 Alias de Pedro Antonio Marín (1930-2008), también conocido como 'Manuel Marulanda Vélez', guerrillero colombiano, principal fundador de las FARC en la década del 60 
cado guerrillero. Así, la construcción de sujetos y objetos puestos en contraposición se analiza aquí sobre una base retórica, esto es, como una gestión de distancias y de diferencias a propósito de una cuestión dada (Meyer, 2013 [2008]).

Para el caso a analizar, la relación entre los discursos tiene carácter polémico. Se trata de una relación agónica y doxológica (Angenot, 1982), construida a partir de la radicalización de posiciones dicotómicas (Dascal, 2008), las tentativas de descalificación-desacreditación del adversario (Kerbrat, 1980), la presencia de un tercero a convencer por parte de quienes asumen roles de proponente y oponente (Plantin, 2003), el acento sobre el antagonismo y la inconmensurabilidad de los puntos de vista opuestos dentro de la confrontación argumentativa (Amossy, 2014).

En ese marco, el contradiscurso se presenta como la forma material enunciativa de la oposición. Recursos retóricos como el elogio y el vituperio, que funcionan bajo lógicas amplificatorias (Aristóteles, 2010; Olave, 2014; Perelman y Obrechts-Tyteca, 1994 [1958]), giran en torno a la profundización de esos posicionamientos opuestos y a la intensificación de la adhesión, por parte del tercero.

El objetivo de intensificar la adhesión es un esfuerzo de quien enuncia por persuadir a su interlocutor. Pero ese esfuerzo está subordinado a la aceptabilidad de los enunciados, esto es, a las condiciones sociohistóricas e ideológicas que evalúan temas, ideas y opiniones como admisibles. Para Angenot (2010), esas regulaciones hacen parte de un discurso social, o conjunto de mecanismos reguladores que homogenizan las retóricas, los lugares comunes y las opiniones, es decir, otorgan aceptabilidad a lo que se dice y se escribe, establecen lo decible en una época y ámbito determinados. La decibilidad, pues, hace parte de las condiciones de producción de los enunciados y deja sus huellas en lo que finalmente es dicho. Desde esta perspectiva, a partir de las relaciones entre lo dicho, lo decible y lo que no llega a decirse, se puede realizar una aproximación teórica y empírica a lo indecible y a su función en los discursos que establecen relaciones oposicionales.

En el análisis, me interesa ligar el recurso retórico de la amplificación con ese aspecto de lo indecible $y$, en particular, con uno de sus procedimientos explorado en otro trabajo anterior, al que he denominado indecibilidad dicha (Olave, 2015). He definido ese procedimiento como un fenómeno de emergencia explícita de lo indecible ajeno en lo decible propio. Lo indecible es aquello que está sujeto a restricciones de autoridad o conveniencia para ser dicho y que aparece en la esfera pública solamente a través de la voz de un opositor en pugna. Lo indecible es dicho en el contradiscurso del adversario, quien lo utiliza para delatar, denunciar, desacreditar y poner en evidencia a su contraparte.

\section{Corpus y método}

He eleccionado dos comunicados públicos como fuentes que refieren la muerte del alias 'el Mono Jojoy': uno gubernamental y el otro guerrillero. Ambos fueron puestos en circulación mediática a través de sus sitios web institucionales, de donde los extraje para este análisis 5 . La difusión se realizó los días 23 y 24 de septiembre de 2010, uno y dos días después de la muerte del guerrillero.

El primer día corresponde a la alocución del presidente de la República, realizada desde Nueva York, con la particularidad de ser la primera vez que el presidente se dirigía a los colombianos a través de la televisión nacional, un mes y medio

5 El sitio web de la Presidencia es http://wsp.presidencia.gov.co/Discursos. La guerrilla de las FARC no centraliza sus comunicados en un solo sitio web, sino que los publican en diversos alojamientos virtuales, como http://farc-ep.co/ y http://anncol.eu/. El particular se extrajo de http://resistenciafariana.blogspot.com.ar/2010/09/mensaje-de-resistenciala-comunidad.html 
después de haberse posicionado en la presidencia. El segundo día corresponde al comunicado guerrillero publicado en la revista virtual Resistencia, como reacción a la alocución presidencial. Este es el primer comunicado insurgente donde se hace referencia a la muerte del alias 'el Mono Jojoy'.

La alocución presidencial es más extensa (1018 palabras) que el comunicado guerrillero (600 palabras), y tuvo mayor despliegue mediático: televisión nacional en directo, sitio web de la presidencia y réplica de fragmentos textuales en los medios informativos. El comunicado, por su parte, apareció en varios sitios web de la insurgencia, pero no tuvo eco en los medios nacionales de información.

Para una contextualización histórica, fueron utilizadas las siguientes fuentes secundarias: informes de ONG sobre el desarrollo del conflicto al finalizar el año 2010 (Ávila, 2011, 2012), estudios históricos sobre la guerrilla de las FARC (CNMH, 2013; Medina, 2009), biografía periodística del alias 'el Mono Jojoy' (Bedoya, 2010) y registro en prensa de la noticia de su muerte (semanarios El Tiempo, El Espectador y Semana, versiones en línea).

El análisis fue inductivo y relacional: inductivo, a partir del principio metodológico de la Teoría fundamentada (Strauss y Corbin, 2003), según el cual las categorías teóricas emergen del análisis del corpus. Relacional, en tanto que el interés consistió en "poner en diálogo" dos textos que representaran dos versiones contrapuestas sobre un mismo hecho; en este caso, sobre la muerte del cabecilla guerrillero. Seguí un procedimiento en tres fases. 1) Selección de un caso de discursividades polémicas (Amossy, 2014) entre comunicados del gobierno y de las FARC, que permitiera analizar los modos de presentar el desacuerdo entre los actores. 2) A partir de la lectura de los textos, establecí énfasis y regularidades de los elementos textuales que transparentaban recursos retóricos y modos de inscribir en el discurso los posicionamientos opuestos entre los actores y sus discursos; realicé esta operación a través de una codificación. 3) Con la ubicación de esos indicios en los textos, planteé relaciones contrastivas y determiné tres categorías teóricas emergentes: amplificación, indecibilidad y contradiscursividad. Estas categorías orientaron la interpretación de los comunicados; construyo esa interpretación a lo largo de la presentación de los resultados y la sintetizo explicítamente en las conclusiones. Las categorías referidas servirán como hipótesis de trabajo para futuros análisis, más allá de este estudio de caso.

La amplificación es un procedimiento retórico que consiste en realzar o destacar un tema a través de recusos como la reiteración, la acumulación y la enumeración (Beristaín, 1995: 44). Para Perelman y Obrechts-Tyteca (1994 [1958]) constituye el principal procedimiento del género epidíctico, a través del cual se logra aumentar la intensidad de la adhesión del auditorio.

La indecibilidad es la propiedad y condición de existencia de aquellos enunciados "impronunciables", "inexpresables" en el espacio público, producto de los sistemas de restricciones explícitas e implícitas que conforman un régimen de "lo que puede y debe ser dicho en una coyuntura determinada", y que Haroche, Henry y Pêcheux (1971: 102) denominan "formaciones ideológicas". En Olave (2015) he explorado críticamente las relaciones diferenciales de esta noción con el marco de la pragmática lingüística ("implicaturas" e "implicituras"), con los conceptos de "presupuesto" y "sobreentendido" (Ducrot, 1984; Kerbrat-Orecchioni, 1986), que no atienden específicamente la dimensión adversarial del silencio. En este sentido, sigo la línea de trabajo de Orlandi (2007 [1992]: 73) en cuanto al estatuto fundante y político que reconoce en el silencio, no una ausencia, sino una resignificación o fundación de significados múltiples.

El término contradiscursividad, por su parte, lo utilizo para referirme al efecto retórico producido por un conjunto de enunciados que establecen una relación agónica o contradictoria contra un discurso que presentan como opuesto y frente al cual disienten (Olave, 2015). Toda vez que se trata de un efecto creado en y a través del 
discurso, la contradiscursividad construye unos modos de oposición política, pero no juzgo esos modos como formas legítimas o no legítimas de contradicción en relaciones de poder, sino que indago en sus lógicas de construcción y funcionamiento retórico.

En los resultados de este artículo expongo la amplificación retórica como regularidad en los textos y describo los modos en que la muerte del cabecilla guerrillero origina la aparición de lo indecible en cada contradiscurso. En las conclusiones, sostengo que el procedimiento de la amplificación es funcional a la construcción de la oposición política en el discurso y, además, refuerza la estrategia retórica de la "indecibilidad dicha”, esto es, la enunciación explícita de lo que el adversario supuestamente no puede ni debe decir en el espacio público. Este tipo de recursos muestra la importancia del papel de lo silenciado en las interacciones polémicas entre el discurso insurgente y el gubernamental.

\section{Resultados}

Ilustraré los resultados a través de ejemplos tomados del corpus, que respaldan la interpretación que propongo. Pretendo guiar al lector en el desarrollo de los comunicados gubernamental y guerrillero, leyéndolos analíticamente en el orden de presentación temática que proponen los mismos textos; como se trata de un análisis relacional, iré destacando alternadamente los recursos que aparecen en uno y otro comunicado, especificando los efectos amplificatorios y los apoyos o evidencias lingüísticas de los cuales se valen.

\subsection{De la amplificación estructurante}

Las lógicas amplificatorias estructuran el contenido de los discursos analizados. Esto significa que, a partir de recursos para intensificar la adhesión del auditorio (Perelman y Obrechts-Tyteca, 1994 [1958]), esas lógicas organizan y dirigen los posicionamientos que los actores hacen de sí mismos, de los otros y de los hechos del conflicto armado, según sus intereses políticos.

La alocución presidencial inicia amplificando positivamente el propio discurso (la primera alocución del Presidente), el lugar de enunciación (Nueva York, la Asamblea de la ONU) y la figura del enunciador (el Presidente, representante internacional de los colombianos). El efecto amplificador aquí se logra a través de una indiferenciación entre el evento protocolario y la alocución, independientes uno del otro, pero solapados en el discurso (1). La indiferenciación se logra a través del determinativo en posición deíctica ("esta") y de la función copulativa del verbo ser, que construye la definición del evento:

(1) Queridos compatriotas: Esta es mi primera alocución a los colombianos. Les estoy hablando desde Nueva York, donde me encuentro representando al país ante la Asamblea de las Naciones Unidas (Presidencia, septiembre 23 de 2010).

El texto progresa hacia formas elogiosas directas e indirectas, a través de las cuales se autoelogia la política de seguridad pública (puesta en equivalencia con la prosperidad, como se ve en el resaltado con negrita añadido del ejemplo 2), y las labores contraguerrilleras de las Fuerzas Armadas. La equivalencia es construida a través de la disposición lógica de orden causal entre los sustantivos "seguridad" y "prosperidad", con el uso de la locución preposicional "gracias a". Los elogios desembocan en la presentación del asesinato de ‘Jojoy' como una muestra de valor, efectividad y contundencia, maximizado además con la superlativización del hecho (subrayado añadido en 2). En este caso, se enfatiza el valor del superlativo a través de la locución adverbial "sin duda”, con función modalizadora de asertividad.

(2) Estamos mostrando al mundo con orgullo el bueno momento que vivimos en Colombia gracias a los avances logrados en seguridad, 
que hoy nos permiten pensar en un futuro de prosperidad para todos.

Estos avances son los resultados de un trabajo valeroso y efectivo de nuestras Fuerzas Armadas (...). La muerte de alias el 'Mono Jojoy' es sin duda el golpe más contundente que se le ha dado a las FARC en toda su historia ${ }^{6}$ (Presidencia, septiembre 23 de 2010).

El comunicado guerrillero, por su parte, establece desde el principio una doble amplificación negativa: de la muerte de 'Jojoy' y de la comunicación gubernamental de esa muerte. Ambas critican un interés belicista del gobierno y se apropian de una voz colectiva (la de "los colombianos" "el pueblo de Colombia y el mundo") para denunciarlo. Se reprochan, además, actitudes de falsedad, amarillismo y crueldad en el otro (subrayados en la cita 3). Esa amplificación se apoya lingüísticamente en la adjetivación orientada negativamente ("macabro", "guerrerista”, "amarillista", "falsa") y en las nominalizaciones que categorizan las acciones y decisiones del gobierno: "triunfalismo macabro" y "euforia guerrerista" para referirse a la alocución presidencial; "prensa amarillista del régimen" para desacreditar la difusión en medios masivos de la muerte de 'Jojoy”; y "una falsa y victoriosa aniquilación de la insurgencia”, nominalización que categoriza el discurso gubernamental de seguridad en el país.

(3) El pueblo de Colombia y el mundo observan el triunfalismo macabro y la euforia guerrerista de la clase gobernante colombiana, hecho perfectamente reflejado en la prensa amarillista del régimen, que acuciosa ha desplegado ediciones especiales, no para lamentar la violencia y clamar por la paz, como demandan los colombianos, sino para cantar una falsa y victoriosa aniquilación de la insurgencia (FARC, septiembre 24 de 2010).
Elogios y vituperios se alternan en el comunicado para exaltar a la guerrilla y a sus medios de información, en contraste con los medios "amarillistas del régimen”. La exaltación aquí amplifica positivamente a la guerrilla como la rebelión superviviente y la resistencia revolucionaria, a través de las nominalizaciones "rebelión insurgente" (para categorizar la lucha guerrillera) y "símbolo revolucionario de resistencia" (en referencia a 'Jojoy') y relaciona al gobierno con la corrupción y la crueldad (cursivas en la cita 4):

(4) Voceros de gobierno y analistas de bolsillo nutren la pretensión que por medio siglo ha amamantado la clase terrateniente y corrompida que gobierna: exterminar por la vía militar a la rebelión insurgente.

Cuán lejos están de la realidad que representan Ias FARC-EP en Colombia, y su símbolo revolucionario de resistencia, guías que hoy se propagan incluso más allá de la América Latina (...)

Queremos corroborar que no nos alegra la muerte de nuestro adversario. Jamás la revista y la emisora Resistencia, órganos informativos de las FARC-EP, han celebrado muerte alguna (FARC, septiembre 24 de 2010).

Las nominalizaciones "analistas de bolsillo" y "clase terrateniente y corrompida" buscan desacreditar la voz gubernamental; además, los verbos "exterminar" (a la guerrilla), "alegrar" y "celebrar" (la muerte del adversario) atribuyen las acciones al gobierno, lo cual le permite al discurso insurgente generar el efecto de crueldad del enemigo.

La alocución presidencial, entre tanto, construye una cadena de amplificaciones positivas (sobre el gobierno y las Fuerzas Armadas) y negativas (sobre las FARC) a través de figuras de adición, por repetición y acumulación de térmi-

6 En adelante, a todas las citas les he añadido subrayados, cursiva o resaltados, sin una notación particular, pero sí explicitadas cada vez para indicar aspectos particulares en el análisis. Ninguna de estas marcas aparecen en los textos originales. 
nos (Mortara, 2000: 211-230)7. Las variaciones de la adición retórica refuerzan las amplificaciones con base en la reiteración, pero también generan percepciones particulares sobre la relación entre el enunciador y su palabra, de un lado, y entre la palabra y la realidad, de otro.

En la primera relación, las figuras aditivas aseguran la convicción, firmeza y confianza de quien enuncia con respecto a lo enunciado. Esta relación se articula a partir del convencimiento y la seguridad sobre lo dicho; la certidumbre declarada permite esos juegos equivalenciales de reiteración y de acumulación. En la segunda relación, la pretensión justificatoria se resuelve a través de las figuras de la adición. La realidad, así, es saturada desde la cantidad, esto es, por abundancia de razones cuya lógica no es otra que el amontonamiento (5). Estas variaciones de la adición retórica funcionan sintácticamente a través de la aparición de sujetos complejos, formados por sintagmas nominales encadenados y relacionados sinonímicamente.

(5) Alias el 'Mono Jojoy', el jefe militar de las Farc, el sanguinario cabecilla responsable de miles de muertes, de miles de secuestros, de tanta destrucción a pequeñas poblaciones, de tantos actos terroristas, de tanto narcotráfico acabando con vidas humanas y con nuestros bosques, ha caído en su madriguera bajo el fuego de las Fuerzas del Estado (Presidencia, septiembre 23 de 2010).

En (5), a partir del vituperio directo (primera nominalización subrayada) se abre una enumeración que culmina en un clímax con otro vituperio, esta vez indirecto (predicación subrayada): la metáfora de la madriguera reduce al guerrillero a la condición de presa, y convierte la información de su muerte en el efecto de una acumulación de causas (Olave, 2012). Idéntica lógica se repite en la inscripción de recursos y formas elogiosas, como la felicitación y el agradecimiento (resaltados con negrita), alrededor de justificaciones del asesinato de ‘Jojoy' (6):

(6) ¡Cuánto, cuánto les debemos los colombianos a estos héroes y a sus comandantes!

Felicito con emoción al señor Ministro de la Defensa (...); al almirante (...), Comandante de las Fuerzas Militares; al mayor general (...); a los oficiales de inteligencia y a los demás comandantes que lideraron esta operación en el terreno. Fue un trabajo conjunto de nuestras fuerzas, que demuestra una vez más que unidos somos más fuertes, que unidos logramos lo que nos proponemos. Gracias, muchas gracias en nombre de todos los colombianos que hoy respiramos un país más tranquilo, sin la sombra asesina del 'Mono Jojoy' (Presidencia, septiembre 23 de 2010).

El comunicado guerrillero responde apelando también a esas figuras de la adición. Se reitera en todo el discurso la referencia peyorativa al gobierno como un "régimen" corrupto y sanguinario, la alusión a la guerrilla como "resistencia" justa y heroica, y la paz como bandera política. Las formas elogiosas y vituperantes rodean siempre esas reiteraciones en el discurso guerrillero. En (7) se ilustran sus tópicos, que se valen de nuevo de la adjetivación negativa (contra el gobierno) y positiva (sobre el mismo enunciador):

(7) No obstante seguimos reclamando una oportunidad para la paz, no para la rendición como obstinada y estúpidamente lo piensa el régimen. Lo que reclamamos ya lo comunicó con meridiana claridad nuestro comandante Alfonso Cano: el único camino es la solución política y pacífica para el conflicto social y armado interno, y en ella somos

7 Angenot (1982: 238-244) las Ilama "Figuras de la aserción”, y "asertividad” a la modalización enfática de la aserción. A propósito del discurso panfletario, el autor advierte efectos sugestivos y "terapéuticos" sobre el lector, a través de la repetición asertiva. 
y seremos factor determinante, las demás estrategias solo contribuyen a prolongar el espiral de la guerra (FARC, septiembre 24 de 2010).

El tópico de la paz está presente en ambos discursos, el gubernamental y el guerrillero; es al mismo tiempo punto de partida y de llegada del conflicto. Alrededor de la paz se amplifican positivamente las acciones y decisiones de los acto- res que la enuncian, se refuerzan sus posicionamientos y se establecen oposiciones entre ellos. Se trata de una paz compartida en el discurso, "escondida" en un lugar desconocido o ignorado por el adversario (subrayados en (8) y (9)), pero inscrita en cada caso, en dimensiones distintas: en la prosperidad y el progreso en tránsito de la misma Colombia, del lado gubernamental, y en la justicia y la democracia de una Nueva Colombia, del lado guerrillero:
(8) Con más moral, con más espíritu, con más determinación seguiremos buscando la paz. Ese es nuestro objetivo: una Colombia en paz (...). Unidos, trabajando juntos por el futuro, estamos abriendo el camino que lleva a la paz, que es el mayor aporte para la prosperidad y el progreso de todos los colombianos (Presidencia, septiembre 23 de 2010).
En (8), las reiteraciones operan por repeticion de la construcción "con más" y el demostrativo "ese" en función pronominal acompañado de la cópula definitoria "es" y el plural sociativo en el posesivo "nuestro". En (9), el tópico de la paz aparece a través de la construcción negativa "no es por la vía...", el autoelogio con los sustantivos positivos "honor", "gloria”, "justicia” y "democracia”, y la nominalización "Nueva Colombia”, para categorizar el proyecto político insurgente.

Del mismo modo, los recursos a la amenaza y a la exhortación del auditorio funcionan diri-
(9) (...) asumimos con disciplina el pensamiento Fariano(...), que claramente y desde siempre han lamentado la violencia, y en cambio hemos defendido y propuesto el diálogo y la paz (...). No es por la vía de la exterminación del contrario que Colombia encontrará la pazy la reconciliación (...). Nos cubre el honor y la gloria de seguir luchando y resistiendo hasta alcanzar una Nueva Colombia, en paz con justicia y democracia (FARC, septiembre 24 de 2010).

gidos por las lógicas amplificatorias. En el primer caso, la amenaza gubernamental refuerza la imagen de la contrainsurgencia como política antiterrorista efectiva y exitosa (10); la amenaza guerrillera, por su parte, desafía al gobierno advirtiendo sobre la inminencia de su expansión en las ciudades ${ }^{8}(11)$. En ambos casos, amenazar es también amplificar la lucha de cada actor, asegurar su continuidad anclándola en el imaginario de la nación vulnerada y vulnerable (cursivas):

8 Las FARC han sido una guerrilla esencialmente rural, desde su nacimiento. La penetración en las ciudades ha figurado en sus planes estratégicos, pero la política de Seguridad Democrática (2002-2010) las hizo replegarse de nuevo en las zonas campesinas, regresar a la llamada "guerra de guerrillas" y abandonar un avance hacia la "guerra de posiciones" en las zonas urbanas. Pese a la muerte de 'Jojoy' y al debilitamiento del Bloque Oriental, al finalizar el año 2010, las FARC contaron con logros militares importantes a raíz de su reacomodación táctica, pero no obtuvieron los mismos resultados a nivel político (Ávila, 2011). Hay que reconocer, no obstante, la existencia de algunos grupos políticos clandestinos desarmados, sin gran impacto hasta el momento, como el Partico Comunista Clandestino Colombiano, PCCC, y el Movimiento Bolivariano, MB (Medina, 2009). 
(10) Una vez más les notifico a los cabecillas de las Farc y a los guerrilleros: ¡Vamos por ustedes! ¡No ahorraremos esfuerzo alguno y ustedes saben que nosotros sabemos cumplir! (...) Colombia, Colombia puede ser un país sin guerrilla, un país sin terrorismo. Y lo vamos a demostrar por la razón o por la fuerza (Presidencia, septiembre 23 de 2010).

En cuanto a la exhortación, es dirigida a colectivos distintos. En el discurso gubernamental, el asesinato de 'Jojoy' sirve como plataforma para incentivar la desmovilización de la tropa guerri-
(11) Esta es la personalidad violenta y excluyente del régimen que enfrentamos, y que pese a los avatares de la confrontación, seguiremos enfrentando mientras tengamos, como hasta hoy, el respaldo popular de las gentes humildes y negadas que engrandecen la resistencia guerrillera. Ahí está el secreto que nos proyecta al futuro tanto en las selvas como en las ciudades de Colombia (FARC, septiembre 24 de 2010).

Ilera, a quienes se apela directamente, pero también para justificar la continuidad de la contrainsurgencia, a través del imperativo de la misión en curso (12).
(12) Es el momento de seguir luchando hasta que todos los violentos, todos los violentos entiendan que el único camino es la desmovilización y la dejación de las armas y la dejación del terrorismo (...). ¡Desmovílicense! Abandonen esta causa perdida y vuelvan a la sociedad y a sus familias (Presidencia, septiembre 23 de 2010).

A su turno, el discurso insurgente desacreditará los llamados a la tropa que realiza el gobierno y convocará a un colectivo aún más amplio, para presentar como engañoso al discurso gubernamental (13). Para el destinatario combatiente, cualquiera sea su bando, el mensaje resulta ser - explícitamente- el mismo: "seguir luchando". En el discurso, los recursos amplificatorios refuerzan modos de inscribir la oposición entre sujetos en disputa. En el siguiente apartado se profundiza sobre esa relación.

\subsection{De la contradiscursividad en la po- lémica}

En el apartado anterior exploré la lógica de la amplificación y principales recursos retóricos utili-
(13) Convocamos a la comunidad nacional e internacionala que no se deje engañar fácilmente con los cantos de sirena que han proclamado el presidente J. M. Santos desde Nueva York y sus esbirros desde los periódicos y micrófonos de Colombia (...). Entre tanto, nos cubre el honor y la gloria de seguir luchando (...) (FARC, septiembre 24 de 2010).

zados. Ahora bien, queda por estudiar el modo en que se movilizan esos recursos para construir relaciones oposicionales. Particularmente, me interesa relevar un procedimiento propio del discurso polémico, mediante el cual los actores buscan poner en evidencia a sus adversarios, en la relación agónica. Esa puesta en evidencia del otro trata de hacer explícito lo que al adversario le resulta indecible, esto es, hacer emerger la indecibilidad a través del discurso de oposición.

En el comunicado guerrillero, la ausencia literal de la referencia al asesinato de 'Jojoy' es un indicio de sus enunciados indecibles. Esa muerte no se nombra, su evidencia lingüística es, precisamente, su ausencia, pero sí se le inscribe dentro de una cadena de hechos difusos, generales y desconocidos ("Ios hechos sucedidos", como se lee en la cita 14). La alocución presidencial, en 
contraste, hace aparecer ese enunciado de múltiples formas nominalizadas: "la baja”, "el golpe más contundente", "un triunfo", "una gran victoria”.

(14) En su momento el Secretariado [de las FARC] habrá de comunicar la realidad de los hechos sucedidos en las selvas del sur de Colombia, por lo mismo no agregamos nada sobre estos acontecimientos (FARC, septiembre 24 de 2010).

En (15), el discurso gubernamental hace emerger en la esfera pública el crimen del secuestro, práctica que resultaría indecible para su contraparte, por inconveniencia política, amplificada además por otros recursos, como la generalización, la adición, la analogía y la adjetivación (subrayados).

(15) El mundo recuerda con horror las escalofriantes imágenes escalofriantes en las que este cabecilla terrorista humillaba a sus indefensos secuestrados recluidos en atroces campos de concentración.

Así terminan los terroristas. Como 'Tirofijo', acosado por las bombas; como 'Raúl Reyes', como Iván Ríos, traicionado por sus hombres, como tantos más que mueren en su ley, que es la ley del crimen y la violencia (Presidencia, septiembre 23 de 2010).

El secuestro es uno de los actos que las FARC se han negado a reconocer durante la historia de la confrontación. En el discurso, esa falta de reconocimiento se ha traducido en silencio (en indecible) o en reformulación (en eufemismo). Desde su consolidación como guerrilla, en la década del 70, hasta los primeros años del presente siglo, el secuestro extorsivo llegó a ser su principal fuente de financiación, junto a los negocios relacionados con la cocaína y la heroína ${ }^{9}$. De cara a la percepción social, el secuestro ha tenido un alto costo político para la guerrilla, sobre todo con la introducción de secuestros a personalidades políticas, a soldados y a policías, desde la década del 90 (CNMH, 2013). En la construcción social de una imagen negativa de la guerrilla, a nivel nacional e internacional, el secuestro ha sido uno de los factores claves. Tanto su indecibilidad como su eufemización, en el discurso guerrillero, han reforzado percepciones de engaño y cinismo, sumadas a la censura del secuestro como crimen.

Al intensificar el rechazo a la guerrilla, los recursos amplificatorios intensifican también la indecibilidad del secuestro. Este crimen no emerge solo como delito condenable, sino además como sevicia y relato del horror, y es presentado como acontecimiento marcado en una memoria universal, que "el mundo recuerda"; de ahí la equivalencia efectuada entre los lugares de reclusión de los secuestrados y los "campos de concentración" nazis ${ }^{10}$. La crueldad atribuida profundiza el carácter indecible del crimen que denuncia, es decir, la imposibilidad de que el responsable - la guerrilla - lo admita.

De otro lado, en (15) se alude también a un suceso puntual de traición en las propias filas

9 "Para las FARC, los recursos provenientes del secuestro han decrecido significativamente desde el 2002, cuando la cifra de secuestrados alcanzaba los 1.120. Entre el 2008 y el 2012, la tendencia continuaba a la baja aunque con un leve aumento hasta el 2011. En el año 2010, a las FARC se le atribuían 82 secuestros. Para el 2011 y 2012, el secuestro siguió descendiendo hasta alcanzar un total de 77 y 20 secuestros, respectivamente" (CNMH, 2013: 289). En febrero de 2012, la guerrilla anunció el cese de esta actividad como fuente de financiación.

10 Esta analogía fue establecida por el expresidente Álvaro Uribe Vélez (2007) en una intervención pública a raíz de la fuga de un soldado secuestrado por las FARC, y de la circulación de videos filmados por ellos mismos, como prueba de supervivencia de sus rehenes. Desde tiempo atrás, el gobierno venía denunciando la existencia de campamentos donde la guerrilla mantenían a sus secuestrados con vida, en condiciones precarias. La denominación de "campos de concentración" para esos campamentos se extendió rápidamente en los medios masivos de comunicación y se asoció con la figura del alias 'el Mono Jojoy', a quien se le acusa de haberlos creado. 
guerrilleras ${ }^{11}$ (se señaló con cursiva: "Iván Ríos, traicionado por sus hombres"), hecho que cuestiona la unidad y lealtad del grupo insurgente $y$, por tanto, es autosuprimido en el discurso guerrillero. En (16) se reitera ese contradiscurso de la traición interna (cursiva), reforzado por la denuncia de las ejecuciones que 'Jojoy' ordenaba dentro de sus filas:

(16) No solo Colombia se libró hoy de un verdugo, también ustedes se han librado de un verdugo que los castigaba con pena de muerte por cualquier sospecha y los mantenía presos en la oscuridad de la jungla.

(...)

Las Farc se están desmoronando por dentro. Al éxito de esta operación contribuyó también gente de las propias Farc, cansada ya de tanta crueldad y del permanente asedio de nuestras Fuerzas (Presidencia, septiembre 23 de 2010).

Tanto las ejecuciones como la traición internas son utilizadas para persuadir hacia la desmovilización. En el subrayado, la metáfora de la guerrilla como un objeto que se va deshaciendo y arruinando refuerza la imagen de decadencia del grupo y se articula con la estrategia contrainsurgente de atacar desde adentro ${ }^{12}$. La decadencia construida en el discurso tiene carácter moral, con efectos en lo político: una guerrilla inhumana deviene en una cierta irracionalidad política; la pérdida de su norte y de sus fines. La figura de 'Jojoy' como "verdugo", reiterada en el fragmento (negritas añadidas), condensa esa doble cara inhumana/irracional de la imagen construida de la guerrilla. Pero además busca justificar la colaboración con el gobierno, equilibrando una traición con otra traición: la primera, la del guerrillero que se desmoviliza o que colabora en las operaciones contra su propio grupo, queda justificada por los actos reprochables y la "crueldad" de esos "verdugos" internos que han traicionado la causa guerrillera, como alias 'Jojoy'. El reconocimiento de la existencia de traidores dentro de la guerrilla, lo mismo que la ejecución de sus propios miembros, emerge aquí como indecibles atribuidos a la insurgencia.

El contradiscurso ataca a partir de la puesta en escena de aquello que el adversario no podría ni debería decir, por falta de conveniencia o de autoridad. En la construcción de sujetos y objetos oposicionales, la contradiscursividad orienta los modos del decir para llenar el discurso propio de aquellos enunciados que el adversario, supuestamente, se ve en la obligación de reprimir o suprimir. En el caso del comunicado guerrillero, el procedimiento es idéntico:

(17) Sabemos que los ejecutores de la guerra del régimen, ni por un minuto piensan que sus bombas de racimo pueden alcanzar a sus soldados y policías que permanecen como nuestros prisioneros de guerra en la selva. Nada les detiene de lanzar sus bombardeos feroces, inclusive asesinar a mansalva a sus propios hombres que dignamente han defendido sus políticas (FARC, septiembre 24 de 2010).

En los subrayados de la cita (17) se alude al riesgo que toma el gobierno al llevar a cabo rescates militares de sus propios miembros, secuestrados por la guerrilla. La muerte de soldados y policías en intentos de rescate resulta indecible para el gobierno, y el discurso guerrillero no solo lo pone

11 Alias Iván Ríos (Manuel de Jesús Muñoz Ortiz) fue el jefe del bloque central de las FARC, traicionado por su guardia de seguridad, quien lo asesinó y se entregó al Ejército colombiano, en marzo de 2008, a cambio de una recompensa ofrecida por el gobierno (CNMH, 2013).

12 Ávila (2012: 23) evalúa el plan contraguerrillero ejecutado durante 2010-2011, y concluye que "a diferencia de la administración Uribe, durante la era Santos, lo que prima son las estrategias de consolidación de territorios y promover las desmovilizaciones, más que el número de abatidos". El contradiscurso gubernamental va a ser esencial en el desarrollo de esas estrategias. 
en evidencia, sino que además lo amplifica con recursos de intensificación (subrayados) y de adición por repetición (cursivas).

Mientras que la intensificación subraya la irracionalidad de los rescates militares, la repetición del posesivo ("sus") atribuye toda la responsabilidad del riesgo de muerte de los secuestrados al gobierno, presentado como régimen belicista. No se diría aquí que esas muertes son ejecutadas por los guerrilleros, a quienes se les ordenaría asesinar a los secuestrados cuando adviertan operaciones de rescate por parte del gobierno.

El rescate militar, bajo estas condiciones, ha generado posiciones encontradas entre la población civil, los analistas del conflicto y los propios secuestrados. La cuestión es debatida sobre precedentes trágicos: el asesinato de muchos retenidos en intentos de rescate, la mayoría de ellos secuestrados políticos ${ }^{13}$. De un lado, se argumenta que el Derecho Internacional Humanitario no proscribe este tipo de operaciones, sino que las regula y limita su empleo, respetando la constitucionalidad nacional, el derecho y deber Estales de defender la libertad de los ciudadanos (Álvarez y Salas, 2013). De otro lado, se considera ilegal por violar los principios de proporcionalidad y necesidad militar, establecidos por el mismo $\mathrm{DIH}$, poner en riesgo la integridad de los rehenes y omitir otras alternativas, como el canje de rehenes entre los bandos enfrentados (el denominado "intercambio humanitario") (Heyck, 2009). En ambas interpretaciones se callarían cosas: el riesgo de provocar la muerte de los retenidos resulta indecible para el gobierno, defensor y ejecutor de rescates militares; y la responsabilidad material de esas muertes violentas es indecible para la guerrilla.

El secuestro, pese a ser el tópico de este contradiscurso, es eludido como indecible propio a través del efecto mitigador del eufemismo, que reformula a los secuestrados como "prisioneros de guerra". Esta denominación tiene intenciones políticas: Ia terminología corresponde al Convenio III de Ginebra (CICR, 1949), que regula esta figura y la inscribe dentro del reconocimiento de un estatus de beligerancia para los actores insurgentes. Esa inscripción les permite atenuar el hecho de la retención forzada del adversario como parte natural de la guerra, y las ejecuciones a las víctimas, como un efecto involuntario de su degradación. Los asesinatos, así, son revestidos de una cierta legalidad que parece excusar a sus ejecutores, o a lo sumo, desplazar las responsabilidades hacia el otro. En función de ese legalismo, los estatutos y reglamentos disciplinarios de las FARC (2007), lo mismo que sus comunicados públicos, han homogenizado el término "prisioneros de guerra" y han hecho del "secuestro" un indecible en su discurso.

En el caso de (18), la contradiscursividad hace emerger las problemáticas sociales de las condiciones de vida del país como acumulación de causas para la continuidad de la insurgencia:

(18) Mientras haya injusticia, desplazados y desterrados, acaparamiento de la tierra y la riqueza, bandas de narcotraficantes y paramilitares cogobernando, impunidad, corrupción, pobreza extrema, falta de garantías para participar políticamente por la vía pacífica y democrática, y mientras haya pérdida de soberanía y saqueo de nuestros recursos naturales, ahí seguirán apareciendo sin cesar los semilleros genuinos para la existencia de las FARC-EP (FARC, septiembre 24 de 2010).

Esas problemáticas son presentadas como indecibles gubernamentales. Su adversario las utili-

13 En 2001, una exministra de Cultura; en 2003, un gobernador, un exministro y ocho soldados; en 2008, once diputados regionales; en 2011, tres policías, estos últimos retenidos desde hacía más de diez años (CNMH, 2013). La secuestrada política que alcanzó mayor visibilidad internacional, la excandidata presidencial Íngrid Betancourth, fue rescatada militarmente en una de las pocas operaciones de este tipo que fueron exitosas. 
za a la manera de imputaciones, como las de corrupción e impunidad estatal, y la de alianzas de narcotraficantes y paramilitares con sectores del gobierno. El contenido de lo indecible, cuando es dicho por el adversario, propone una versión de la realidad y la ajusta a los intereses propios, la esquematiza y la "da a ver" (Grize, 1990, citado por Arnoux, 2008: 46) de un modo particular.

La selección estratégica de esos supuestos indecibles gubernamentales se basa en la apelación a hechos que el auditorio puede reconocer y condenar, como el desplazamiento forzado y la sobreexplotación de la tierra: conflictos agrarios vigentes en el país. Las problemáticas sociales son dadas a ver a través del contradiscurso; algunas de ellas, como la violencia contra la oposición de izquierda (subrayado en la cita 19), se reiteran en el comunicado guerrillero para reforzar la imagen positiva de sí mismos y la trama justificatoria de las acusaciones:

(19) Por el contrario [del gobierno], asumimos con disciplina el pensamiento Fariano y los lineamientos del Estado Mayor y el Secretariado Nacional, que claramente y desde siempre han lamentado la violencia, y en cambio hemos defendido y propuesto el dialogo y la paz. Acaso no fue esa la inspiración de la exterminada Unión Patriótica ${ }^{14}$ ¿y no son los mismos lineamientos democráticos, pluralistas y pacifistas del Movimiento Bolivariano por la Nueva Colombia? (FARC, septiembre 24 de 2010).

El contradiscurso imputa al gobierno la responsabilidad sobre las problemáticas sociales. Se construye, así, un panorama nacional de crisis y decadencia, que viabiliza la desacreditación del adversario y lo enfrenta a lo que él no podría admitir ni decir, al exponerlo en las arenas públicas.
La polémica, entonces, se desplaza del juego manipulatorio de la palabra proferida por el adversario hacia el juego con la palabra que el otro no se atreve a proferir. El enunciado contradiscursivo, en síntesis, se construye con un material oscuro: está hecho de los supuestos silencios estratégicos del otro.

\section{Conclusiones}

A través de dos comunicados, uno gubernamental y el otro guerrillero, al respecto de la muerte del 'Mono Jojoy', he analizado la inscripción de oposiciones políticas en el discurso. La amplificación retórica, según se evidencia, urde una trama laudatoria y vituperante que exalta y desacredita de acuerdo con el trasfondo político de cada actor. El uso de figuras de la adición (repeticiones y acumulaciones) respalda la amplificación de lo referido en cada discurso y, sobre todo, construye una relación oposicional también amplificada, que establece distancias entre los actores.

Amplificar y contradecir en estos discursos se lleva a cabo enfocando aquello que supuestamente el adversario no puede ni debe decir. En los ejemplos extraídos ilustré el modo como opera ese tipo de atribución, cuya lógica podemos parafrasear así: "no eres capaz de admitir tus crímenes; por eso yo los denuncio". Se trata, como vemos, de un modo de desacreditar al adversario, pero también de mostrarse como el que es capaz de poner al otro en evidencia. Así, se amplifica negativamente lo que el adversario supuestamente calla, y se amplifican positivamente las acciones y decisiones propias.

Este tipo de recursos muestra la importancia del papel de lo silenciado en las interacciones polémicas entre el discurso insurgente y el gubernamental, en medio del conflicto armado

14 Partido político de izquierda, nacido en 1985 como producto de un proceso de paz entre la guerrilla y el gobierno del expresidente Belisario Betancourt (1982-1986). La mayor parte de sus miembros, incluyendo dirigentes y candidatos presidenciales, fue asesinada sistemáticamente, hasta 1990. 
colombiano. El caso de los comunicados sobre la muerte de 'Jojoy' nos ayuda a entender cómo los discursos en confrontación entre la guerrilla y el gobierno colombiano llenan los espacios silenciados que deja el adversario; el contenido de ese "llenado" amplifica la distancia y profundiza la diferencia entre los actores, de manera que el desacuerdo político y los efectos mortales de la guerra, es decir, las cuestiones de fondo, quedan desplazadas o anuladas por esas formas amplificadas con las cuales se construye negativamente al otro y positivamente a sí mismo.

Ahora bien, ver lo indecible funcionando en las retóricas construidas por estos actores del conflicto armado ayuda a explicar la prolongación de la guerra por más de 50 años. Acusar al otro de "no estar diciéndolo todo", esto es, de silenciar a propósito, eleva una sospecha permanente sobre el adversario, que impide la coexistencia entre visiones distintas sobre la realidad y trunca la posibilidad de que el debate político reemplace la lucha con las armas; de ahí que la única opción sea la anulación —discursiva-y la aniquilación -física- del enemigo. Los discursos que presentaron la muerte del líder militar de las FARC dejan ver que los usos de la indecibilidad en medio de la guerra pueden profundizar y prolongar esa última opción.

En síntesis, en esos procesos amplificatorios de cada discurso he mostrado que la oposición política se realiza no solo a través de lo dicho, sino además de la indecibilidad del otro que es dicha por el adversario. La oposición construida en los discursos se esfuerza en llenar el espacio público con la desacreditación de la palabra ajena, denunciarla como indecible y exponerla como una puesta en evidencia. En ese esfuerzo, permanece silenciado lo indecible-propio, hasta que el actor en confrontación lo construye, lo denuncia y lo expone también en las arenas públicas. De este modo, la oposición política termina tratándose de un hacer emerger (lo que el adversario no se atrevería a decir), con el objetivo de hacer sumergir (lo que quien enuncia tampoco se atrevería a decir) (Olave, 2015).
Con todo, he pretendido aproximarme a la comprensión de las relaciones de oposición en los discursos del conflicto armado, de cara a los procesos de negociación política entre este grupo insurgente y el gobierno colombiano. En el marco de los esfuerzos actuales por encontrar salidas a la violencia armada a través del diálogo y la concertación (GESCAL, 2015), los procesos de paz interpelan y convocan el estudio de las interacciones polémicas, con particular énfasis en la construcción retórica de la contradiscursividad $y$, en este sentido, los analistas del discurso nos sentimos también urgentemente interpelados y convocados. El estudio de la amplificación, la indecibilidad y la contradiscursividad queda proyectado hacia el análisis de los discursos estatales e insurgentes en el contexto del postconflicto armado colombiano, espacio donde seguirán jugándose formas de distanciamiento y de acercamiento construidas en las retóricas en divergencia. En el cruce de esas voces, al que atiende la retórica, anida el conflicto social; pero también adquiere sentido la democracia.

\section{Bibliografía citada}

Álvarez, Ariel y Salas, Alejandro, 2013: "El rescate de rehenes y el Derecho Internacional Humanitario”, Estudios de Seguridad y Defensa 1, 139-166.

Amossy, Ruth, 2014: Apologie de la polémique, Paris: PUF.

Angenot, Marc, 1982: La parole pamphlétaire. Contribution à la typologie des discours modernes, Paris: Payot.

Angenot, Marc, 2010: El discurso social. Los límites históricos de lo pensable y lo decible, Buenos Aires: Siglo XXI.

Arnoux, Elvira Narvaja de, 2008: Los discursos sobre la nación y el lenguaje en la formación del Estado (Chile, 1842-1862). Estudio glotopolítico, Buenos Aires: Arcos. 
Arrázola, María, octubre 9 de 2010: Los secretos del "Mono Jojoy", Periódico El Espectador [disponible en http://www.elespectador.com/impreso/ judicial/articuloimpreso-228823-los-secretosdel-mono-jojoy, fecha de consulta: 5 de junio de 2015].

ÁvILA, Ariel, 2011: "De la guerra de 'Jojoy’ a la guerra de 'Cano'. Informe de la Corporación Nuevo Arco Iris", Revista Arcanos 16, 28-47.

ÁviLA, Ariel, 2012: "Las FARC, la guerra que el país no quiere ver" en León Valencia (dir.): Informe anual de la Corporación Nuevo Arco Iris: Política y violencia en 2011, "Las cuentas no son tan alegres”, Bogotá: Observatorio del conflicto armado.

Bedoya, Jineth, 2010: Vida y muerte del Mono Jojoy, Bogotá: Planeta e Intermedio editores.

Botero, Jorge (dir.), 2010: "Antes de la tormenta. La última entrevista al Mono Jojoy" [disponible en https://www.youtube.com/ watch?V=Y5Arg7CZUg4, fecha de consulta: 11 de junio de 2015].

Beristán, Helena, 1995: Diccionario de retórica y poética, séptima edición, México: Porrúa.

CICR (Comité Internacional de la Cruz Roja), 1949: III Convenio de Ginebra del 12 de agosto de 1949, relativo al trato debido a los prisioneros de guerra [disponible en http://www.cruzroja.es/dih/ pdf/III_Convenio_Ginebra_12_Agosto_1949_trato_prisioneros_guerra.pdf, fecha de consulta: 10 de junio de 2015].

CNMH (Centro Nacional de Memoria Histórica), 2013: Guerrilla y Población Civil. Trayectoria de las FARC 1949-2013, Bogotá: Imprenta Nacional.

DascaL, Marcelo, 2008: "Dichotomies and types of debates" en Franz Van Eemeren y Bart Garssen (eds.): Controversy and Confrontation, Amsterdam/Philadephia: Benjamins, 27-49.
Ducrot, Oswald, 1984: El decir y lo dicho, Buenos Aires: Hachette.

FARC, 2007: "Estatuto. Reglamento de Régimen disciplinario. Normas de comando. Aprobado en 1978 y actualizado por la Novena Conferencia de las Farc-Ep" [disponible en http://farc-ep.co/wpcontent/uploads/2013/10/Estatutos.pdf, fecha de consulta: 5 de junio de 2015].

FARC, septiembre 24 de 2010: "De Resistencia, a la comunidad nacional e internacional, con motivo de los acontecimientos en las selvas del sur de Colombia" [disponible en http://resistenciafariana.blogspot.com.ar/2010/09/mensaje-de-resistencia-la-comunidad.html, fecha de consulta: 1 de junio de 2015].

GESCAL (Grupo de estudios sobre Colombia y América Latina), 2015: La paz en Colombia. Dossier de la Revista Cuadernos del Gescal 2,1, 13-218 [disponible en http://gescal.org/?p=315, fecha de consulta: 30 de septiembre de 2015].

Haroche, C., P. Henry y M. Pécheux, 1971: "La sémantique et la coupure sau- ssurienne: langue, langage, discours", Langages, 6e année 24, 93-106.

Heyck, Ana, 2009: "Análisis del acuerdo humanitario como alternativa de negociación para lograr la libertad de los secuestrados políticos en Colombia”, Revista Paz y Conflictos 2, 82-98.

Kerbrat-Orecchioni, Catherine, 1985: L'implicit, Paris: ArmandCollin.

Kerbrat-Orecchioni, Catherine, 1980: El discurso polémico, Lyon: Presses Universitaires de Lyon.

Medina, Carlos, 2009: Farc-Ep. Notas para una historia política, Bogotá: Universidad Nacional de Colombia.

Meyer, Michel, 2013 [2008]: Principia Rhetorica. Una teoría general de la argumentación, Buenos Aires: Amorrortu. 
Molano, Alfredo, 1994: "Camino de huyentes" en Trochas y fusiles, Bogotá: El Áncora, 37-42.

Mortara, Bice, 2000: Manual de Retórica, Madrid: Cátedra.

Olave, Giohanny, 2012: “La construcción retórica del conflicto armado colombiano: Metáfora y legitimación del carácter bélico del conflicto", Signos, Estudios de Lingüística 45(80), 300-321 [disponible en http://www.scielo. cl/scielo.php?script=sci_arttext\&pid=S0718$09342012000300004 \&$ Ing=es\&nrm=iso\&tlng=es, fecha de consulta: 20 de marzo de 2015].

Olave, Giohanny, 2014: "Elogio político y argumentación en los discursos presidenciales de Juan Manuel Santos", en Elvira Narvaja de Arnoux y Verónica Zaccari (coords.): Discurso y política en Sudamérica, Buenos Aires: Biblos, 279-358.

Olave, Giohanny, 2015: "Decir lo que el adversario calla. El problema de la indecibilidad en el conflicto armado colombiano, ALED 15(2), 79-98.

Orlandi, Eni, 2007 [1992]: As formas do silêncio, sexta edición, Campinas: Unicamp.

Perelman, Chaïm y Lucie Olbrechts-TytecA, 1994 [1958]): Tratado de la argumentación. La nueva retórica, Madrid: Gredos.

Periódico Eltiempo.com, diciembre 20 de 2010: "El Ejército da de baja al jefe guerrillero 'Mono Jojoy"” en Especial Periódico El Tiempo [disponible en http://e.eltiempo.com/media/produccion/ especial2010/index.html, fecha de consulta: 3 de junio de 2015].

Plantin, Christian, 2003: "Des polémistes aux polémiqueurs" en Gilles DeclercQ (ed.): La parole polémique, Paris: Champion, 377-408

Presidencia de la República de Colombia, 23 de septiembre de 2010: "Alocución del Presidente Juan Manuel Santos Calderón, luego de la baja de alias el "Mono Jojoy'” [disponible en http://wsp.
presidencia.gov.co/Prensa/2010/Septiembre/Paginas/20100923_13.aspx, fecha de consulta: 4 de junio de 2015].

Revista Semana, septiembre 23 de 2010: "Así fue la operación "Sodoma" que dio muerte a 'Jojoy"” [disponible en http://www.semana.com/nacion/ articulo/asi-operacion-sodoma-dio-muertejojoy/122357-3, fecha de consulta: 5 de junio de 2015].

URIBE, Álvaro, 2007: "Palabras del presidente Uribe durante el Consejo Comunitario en San Agustín, Huila" [disponible en http://web.presidencia.gov. co/discursos/discursos2007/mayo/cc_huila.htm, fecha de consulta: 12 de junio de 2015]. 